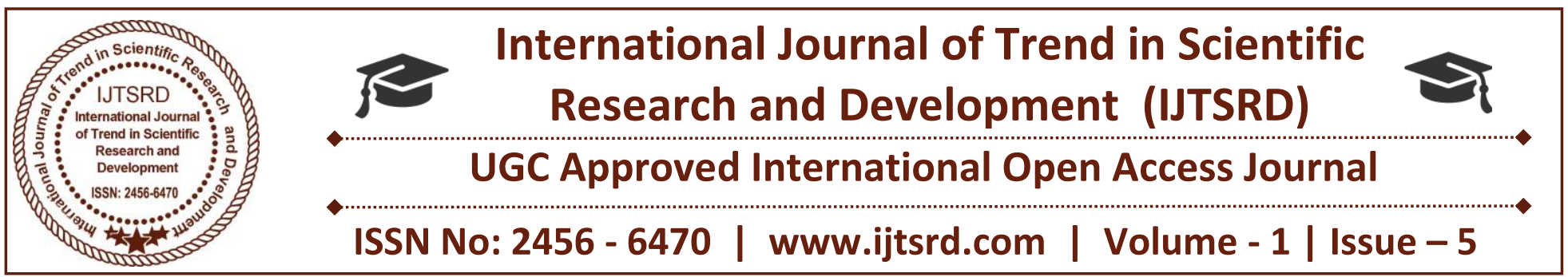

\title{
Social Media as A Global Platform for Business and Branding: Trends, Opportunities and Challenges
}

\author{
Dr. Nagraj Halliyavar \\ Associate Professor, \\ Dept of Communication and Journalism \\ Karnatak University, Dharwad, Karnataka
}

\author{
Shruthi PK \\ PhD Scholar, \\ Dept of Communication and Journalism \\ Karnatak University, Dharwad, Karnataka
}

\section{ABSTRACT}

Social media is emerging as the most successful platform for business promotion. In the digital era, every brand wants to prove its existence on social media channels. Because the popularity of social media has reached the peak. Knowing this fact, social media channels too innovating new marketing tools which can help these companies. A few years ago companies were solely depending on print and electronic media for promotional activities. Social media has arrived like a boon for these companies. Brands do not have to invest a huge amount of money for branding and advertisements. The latest trend on social media marketing is conveying a message that the business world is only for those who can think out of the box. Brands are competition with each other to attract more customers by attractive social media posts. Social media has given a chance for brands to unleash their creativity while fulfilling their marketing tasks. Indian brands especially start-ups have an easy access to international market. Their existence is recognized by global audience. All these are possible due to the advent of social media.

This research paper will analyze the ongoing trends on social media marketing and also opportunities for brands. It will find out the challenges faced by the brands on social media channels. It will highlight the power of social media in introducing the companies to global audience.
Keywords: Social media, Global Platform, Business, Branding

\section{INTRODUCTION}

Gone are the days when communication channels were scarce and people had to rely on a few mediums to convey their messages. Be it individuals or local businesses, the communication gap was one of the major reasons why generations took time to experience growth. Today, when we have hundreds of options to connect and communicate, things have become easy, achievable and within reach.

The reach of social media is so wide that sometimes it becomes really hard to observe how it has changed us and the entire world. While it's true that most of the people around the world are collectively on social media, thanks to the smart phones, mobile devices and unlimited internet because they all when combined together balance our connection with social media platforms.

When a majority of our population is getting breaking news through social media, our entrepreneur community is busy managing their brand reputation on these channels. The impact that social media platforms have had on customer service is exceptional. Social media as a natural medium of communication is facilitating the business 
relationships in a more productive and time-saving environment.

While the core idea behind a majority of social media platforms was to connect people, these channels have ultimately turned into hard-to-ignore business tools. The hundreds of social media channels available today allow businesses to connect with their existing and potential customers in different ways.

Social media is not only helping the businesses with increased sales, but by understanding the customer behaviour and buyer psychology through social media; our entrepreneurs are getting prepared for the future.

\section{OBJECTIVES}

The objectives are framed in accordance with the need of the researcher to analyze the role of social media as a global platform for business and branding

\section{The three main objectives are}

$>$ To analyse the ongoing trends on social media marketing

$>$ To examine challenges faced by companies while promoting their businesses at the global level on social media platforms

$>$ To find out the opportunities for companies to create the brand image on global level through social media platforms

\section{METHODOLOGY}

Qualitative method is used for this research study. The study was conducted in March 2017. Primary data is collected by questionnaire and interviews. The respondents are the business owners and freelancers. These respondents are promoting their services on various social media platforms. Respondents are from different streams like content marketing, automobile industry, writing services and digital marketing. Questionnaires were emailed to the respondents and it consisted both open ended and closed ended questions.

\section{DATA ANALYSIS}

The preferred social media channel for business promotion and branding

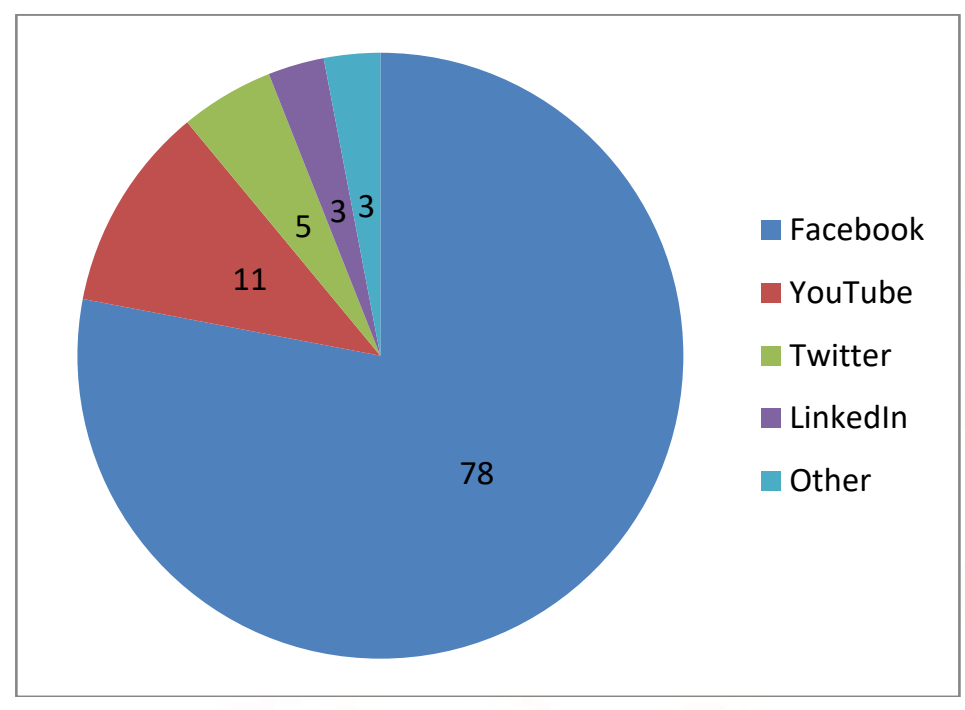

Facebook is the most popular social media channel among the respondents. $78 \%$ of the respondents are giving first preference to Facebook. $11 \%$ the respondents prefer YouTube whereas $5 \%$ of the respondents preferring Twitter over other social media. LinkedIn is used by $3 \%$ of the respondents and $3 \%$ of the respondents have revealed that they use other social media channels for business promotions and branding.

\section{The growth of business through social media promotion}

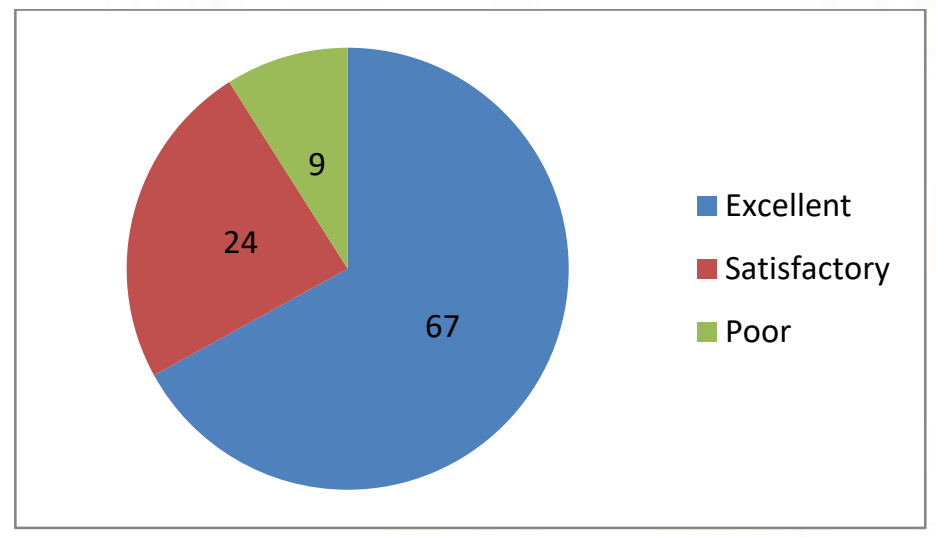

$67 \%$ are agree that social media is a lifeblood for their business promotion activities. They are highly depending on social media channels. While $24 \%$ of the respondents believe that social media is a good medium for brand building, but it is not the most reliable source to drive sales and investing a lot of time in social media doesn't offer higher ROI than other digital and traditional marketing methods. 9\% respondents believe that using social media for business promotion is not a very beneficial growth element. They believe that social media marketing is 
niche specific and cannot bring positive results for all kinds of businesses. Lack of knowledge is also an issue that causes many business owners and freelancers to stay away from promotional activities on social media. Majority of respondents from this segment found that the investment and efforts they made in business promotion through social media didn't bring expected results, while with the other marketing methods they were successful in getting good results.

\section{Active role played by the social media in persuading international customers}

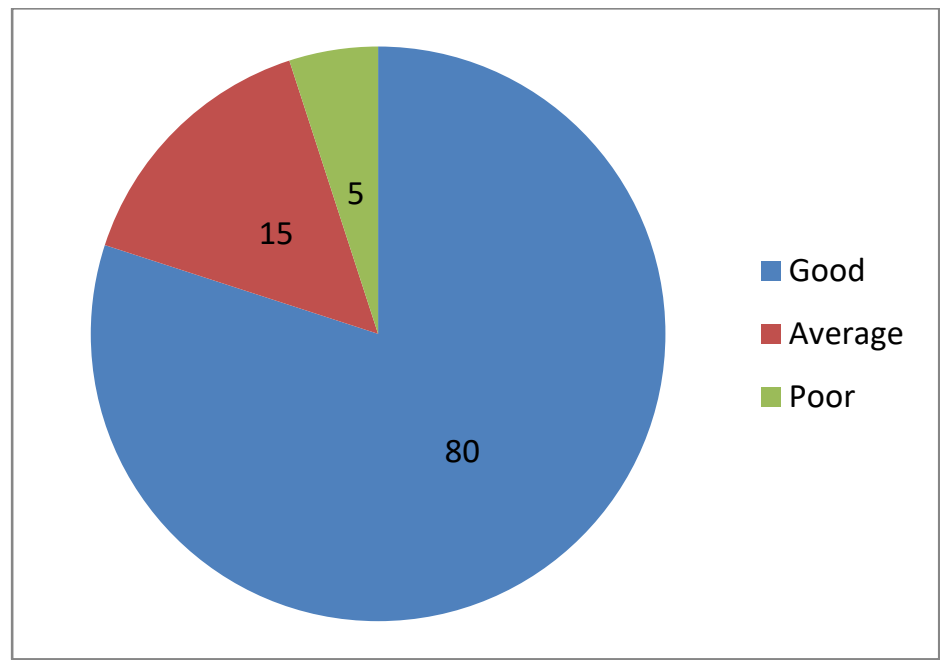

The main goal of any marketing strategy is to persuade and influence potential buyers. When it comes to social media marketing for business, the campaigns must be geared towards persuading the audience towards a predetermines sales funnel. Be it global or local buyers, social media marketers need to master the art of persuasion. For $76 \%$ of the respondents that drive sales from international market, social media is one of the most preferred marketing mediums. Here the majority of businesses offer services and $23 \%$ percent of the respondents deal in both products and services. For $21 \%$ of the respondents who market their business globally on social media have experienced an average growth in sales. According to $13 \%$ of the respondents, social media is not a suitable channel for those willing to drive sales from international customer base. $83 \%$ of respondents believe that having a strong audience base on social media helped them achieve trust of the international buyers.

\section{Problems encountered during social media marketing}

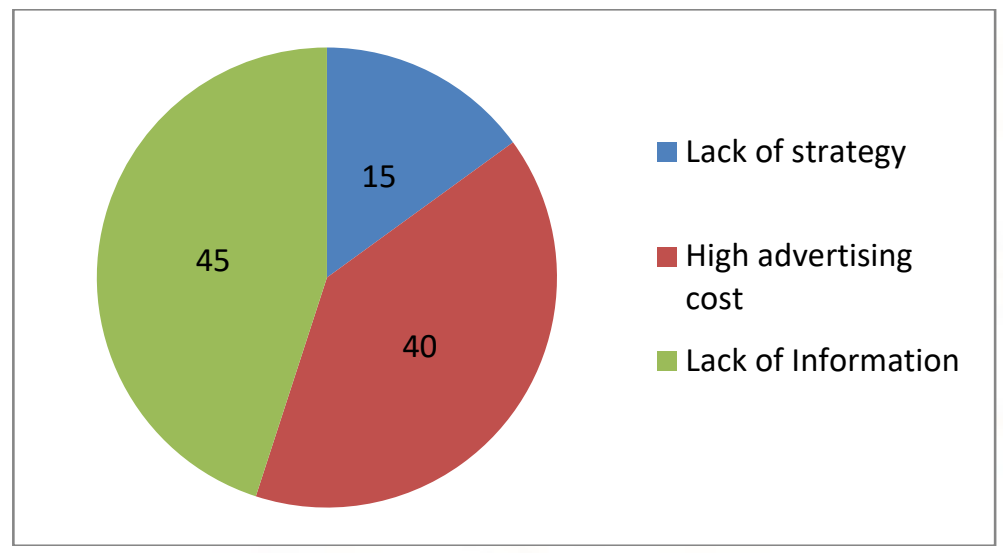

Driving business success through social media marketing is not everyone's cup of tea. When asked about the challenges businesses find when marketing their businesses on these platforms, $77 \%$ of the respondents said that they do not have a documented strategy for social media marketing. $42 \%$ of the respondents find high advertising cost the reason behind why they do not advertise on social media platforms. $62 \%$ of the respondents believe that lack of information and guidance keeps them away from social media marketing. These respondents say that they don't know about choosing the right social media channels for their business. Majority of this group admits that they find it hard to discover their target audience on social media.

\section{OTHER FINDINGS}

> A majority of business owners are not aware about advertising on social media channels

$>$ Maximum number of businesses still do not have a documented content marketing strategy

$>$ Facebook and LinkedIn are the most powerful tools business owners use for personal and business branding

$>$ Businesses prefer social media platforms that enable them have an online store or the ability to showcase products and services. Facebook tops the list of the most used social channels

$>$ Businesses, both small and medium are choosing digital marketing channels over traditional marketing mediums

$>$ Some businesses also use unethical tactics known as 'black-hat' techniques to gain followers and actions on published content 
$>$ A large number of businesses still find social media marketing a complex and time consuming marketing method

> Only a small number of business owners use automation in social media marketing and content creation

\section{CONCLUSION}

As the business competitors improve their online presence, the need for strong business identity on social platforms grows. Building a recognizable brand through social media not only adds credibility, but it also helps gain followers. A successful social media marketing strategy for a business brings new business opportunities too.

It's important for social media marketers to ensure their activities help establish a clear identity of their brand. Many businesses are focusing on social media marketing and are winning followers and shares. The right way to do so it to educate audience while keeping the brand goals and services in mind.

To solve the social media marketing puzzle, businesses must remember that they can succeed if they can dive into their audience's culture. If a business can successfully create a relevant culture, these digital technologies can turn out to be a driving engine for growth. Social media has not only created the possibilities and opportunities, but it has also paved the way for effective customer service, business marketing and increased brand awareness.

\section{BIBLIOGRAPHY}

1) Dixon and Bouma(1984), "The Research Process", London, Oxford University Press

2) Guptha and Hithesh Guptha (2011), "Research Methodology", Delhi, International Books House Pvt Ltd

3) Braude, R. (2009), "Social Media's Effect on Consumer Perception of Organizational Reputation and Innovation", Master of Arts in Public Relations Thesis, Rowan University

4) Aaker, D.A. (1991), Managing Brand Equity: Capitalizing on the Value of a Brand Name, The Free Press, New York

5) Chunawala S.A(2006), Advertising Sales and Promotion Management, 2nd Edition, Himalaya Pub, Mumbai
6) Kelley, Jugenheimer(2008), Advertising Media Planning: A Brand Management Approach, 1st Edition, 2008, PHI, New Delhi

7) Ogilvy, (1985), Ogilvy on Advertising, Vintage Books

8) Pant, H, (2007), Advertising \& Media, ABD Publisher

9) White, R. (2000), Advertising (Fourth Edition ed), McGraw Hill Publishing Company

10) William Leiss, S. K. (2005), Social communication in advertising consumption in the mediated marketplace, Routledge Taylor and Franchis 